\title{
Achieving commonality in interpersonal communication: Shared reality and memory processes
}

\author{
Gerald Echterhoff \\ University of Muenster, Muenster, Germany
}

In the lead article, Yoshi Kashima (2014) reviews and conceptually integrates studies on the processes underlying the construction of socially and culturally shared knowledge. The result is an assembly of research to form a bigger picture. The analyses are informed by insights into conversational, cognitive, behavioural, and motivational mechanisms, and this constellation can be informative and inspiring not only to social psychologists, but to scholars from different fields, including cognition, psycholinguistics, sociology, and anthropology. As a social psychologist, I am particularly impressed by the keen analysis of the interplay between the relational, informational and epistemic functions of shared knowledge (illustrated with the connectivityinformativeness dilemma), and how this interplay is fleshed out at the interpersonal, intragroup and intergroup level. Over the course of the article, the reader learns about various implications of the present approach to cultural meaning making that can contribute to a better understanding of various key psychological phenomena, including the dissemination of stereotypes, the creation of interpersonal relationships, effects of social identification, and conditions for interpersonal mimicry.

In a nutshell, the breadth and depth of the contribution is remarkable. There were only a few open issues that came up when I read the article. For instance, while it is crystalclear that the author himself has made innovative and elegant use of experimentation in his own empirical work, I was not sure how to weigh exactly the comments on experimental methodology at the beginning. In the fifth paragraph, the author draws on a classical methodological distinction in psychology (e.g. Dilthey, 1894) to outline an imbalance of models of scientific investigation in cultural psychology. He juxtaposes a (dominant) natural-science approach, which aims at causal explanation through the method of experimentation, and a (peripheral) humanitiesinspired approach, which is devoted to the understanding

Correspondence: Gerald Echterhoff, Social Psychology Group, Department of Psychology, University of Münster, D-48149 Münster, Germany. Email: g.echterhoff@uni-muenster.de

Commentary on the lead article 'Meaning, Grounding, and the Construction of Social Reality' by Yoshi Kashima in the Asian Journal of Social Psychology.

Received 29 November 2013; accepted 24 December 2013.

and interpretation of meaning through hermeneutic methods. Then, 'attempts to redress this state of affairs' are characterized as 'bringing meaning back from the cold.' I felt that the overtone of this passage was slightly too critical of experimentation. Of course, many studies on communicative and cultural dynamics of meaning making, several of which are mentioned in the lead article, have fruitfully employed experimental manipulations to test predictions about causal processes such as the antecedents and effects of activating culturally relevant knowledge (Chiu \& Hong, 2007). However, rather than dwelling on the contrasts between the two, unequally popular, traditions, and thus conjuring up erstwhile methodological disputes, scholars should be alert to the benefits of a context-sensitive, flexible use of methods from the one or other tradition. It would be interesting to identify specific domains or types of research questions in the psychology of culture, for which the use of experimental methods is more or less feasible. For instance, non-experimental methods can and should be used whenever it is difficult, impossible, or ethically irresponsible to employ experimental manipulations. In the present domain, this might be true for influences of socialization or acculturation on grounding, which can hardly be studied experimentally.

My main comments refer to the type of commonality or alignment achieved in interpersonal communication (common ground, shared reality) and the role of memory processes in the fading, or shared forgetting, of information in knowledge transmission. The author highlights conversational grounding, that is, the mutual negotiation of, and agreement on, common ground, as a key process in the creation of meaning and cultural knowledge. According to a pivotal definition, common ground consists of 'the propositions whose truth he [a speaker; our addition] takes for granted as part of the background of the conversation' (Stalnaker, 1978, p. 320). In subsequent work, common ground has been characterized as the set of information that conversation partners take for granted as mutually understood (Clark \& Carlson, 1981; Clark \& Schaefer, 1989), or, simply put, the partners' sense that they are talking about the same thing (Brennan, 1998). In the lead article, the original psycholinguistic notion of grounding is illustrated with an exchange between two communication partners, Adam and Ben, who jointly establish the meaning of Adam's utterance 'Gary bought a ring.' 
It is one merit of the present paper that it fathoms the broader social-psychological implications of grounding. In the example, the two interlocutors not only ensure the mutual understanding of the focal information at hand (i.e. Gary planning to marry Mary); their exchange also takes for granted the quality of the relevant social relationships, an array of background knowledge and presumptions such as gender stereotypes and social scripts (here, on the steps toward marriage), as well as expectations and norms about future behaviour and actions (such as acting in accordance with the grounded information, for instance, offering Mary a seat next to Gary at the next team dinner). Also, as Kashima (2014) points out in another passage, grounded information becomes 'part of a shared reality' between the interlocutors. It is the relation between common ground and shared reality (Echterhoff, Higgins \& Levine, 2009) that I would like to examine here. In brief, shared reality involves not only mutual understanding of what is meant, what I would refer to as conceptual alignment, but also interpersonally shared judgments and evaluations of the topic. Thus, over and above conceptual alignment, shared reality also emphasizes evaluative alignment between interaction partners. In the following I develop this argument in more detail.

According to a current definition (Echterhoff, Higgins et al., 2009; also see Echterhoff, 2010), shared reality is the product of the motivated process of experiencing a commonality of inner states (e.g. attitudes, impressions, or judgments) about the world. Shared reality requires that people infer or know another person's inner state and are aware of the target of this inner state (e.g. a new colleague at work, the planned marriage between two acquaintances, or a religious issue). It also involves the experience of a connection with the other person (Echterhoff, Kopietz \& Higgins, 2013). Creating the commonality is driven by fundamental human needs and motives, specifically the (epistemic) need for a confident understanding of the world and the (affiliative-relational) need to connect with others (Echterhoff, Lang, Krämer \& Higgins, 2009; Kopietz, Hellmann, Higgins \& Echterhoff, 2010). The two needs are closely intertwined in the operation of shared reality. For instance, by creating a shared reality about a newcomer after his or her first day at a workplace, the old members of the work team can both fulfill their epistemic need for a confident judgment and confirm or strengthen their mutual relationship.

Some interaction partners (e.g. ingroup members) are preferred over others (e.g. outgroup members) as partners for shared reality creation because the interaction with them is perceived as more likely to satisfy these epistemic and relational needs. Indeed, studies using the saying-isbelieving paradigm, some of which are also mentioned in Kashima's article, have provided evidence that is consistent with shared-reality theory. For instance, in some saying-is- believing studies the audience of a message about a target person was either a member of the communicators' ingroup or a member of the communicators' outgroup (Echterhoff, Higgins \& Groll, 2005; Echterhoff, Higgins, Kopietz \& Groll, 2008). While communicators adapted, or 'tuned,' their message to both audiences, only those addressing an ingroup audience, but not those addressing an outgroup audience, incorporated the audience-tuned view into their own memory representation of the target person. Additional evidence suggested that communicators were more motivated and willing to create a shared reality with the ingroup audience than with the outgroup audience.

The lead article refers to this body of research to illustrate the motivational and social conditions for the communicators' experience of having grounded information as 'real' and mutually accepted. Indeed, we (Echterhoff, Higgins et al., 2009) have argued that successful grounding is a condition, or building block, for shared reality. However, we have also argued that shared reality goes beyond common ground. Consider the saying-is-believing effect as an instance of shared-reality creation. The key outcome in saying-is-believing studies is a commonality of evaluative, or valenced, representations about a target person among communicator and audience. In this respect, the audiencetuning memory effect captures evaluative alignment between communicator and audience regarding an object of evaluation (see Echterhoff et al., 2013; Higgins, 2012).

This commonality refers not only to what something is but, given what it is, how it should be judged or evaluated. Psycholinguistic accounts of common ground primarily address commonality between communication partners at the conceptual level regarding what something is and how they refer to it (Clark \& Schaefer, 1989; Clark \& Wilkes-Gibbs, 1986). The key outcome measures in psycholinguistic research, such as an addressee's successful decoding of a speaker's verbal reference (e.g. Clark \& Wilkes-Gibbs, 1986; Schober \& Clark, 1989) or lexical entrainment (Brennan \& Clark, 1996), represent (temporary) conceptual alignment between conversation partners (also see Pickering \& Garrod, 2004). Conceptual alignment requires partner-specific agreement about how to conceptualize and describe a target referent, for example, by agreeing on the reference 'sad rabbit' to describe an ambiguous tangram figure (Clark \& Wilkes-Gibbs, 1986).

Hence, common ground entails conceptual alignment, but not necessarily evaluative alignment. In other words, agreement between people about the referent of a description does not mean that they have a shared reality regarding how to evaluate that referent. For instance, there can be common ground between Israelis and Palestinians, in the sense of a shared reference, regarding what is referred to by the expression 'Road Map' (which formulates steps toward a two state solution). However, any such agreement on the reference of 'Road Map' would not mean that they agreed 
in their evaluation of the Road Map. The difference can also be illustrated with the key example from the lead article. The two interlocutors, Adam and Ben, may quickly negotiate and ground the meaning of Adam's brief remark ('Gary bought a ring') and thus achieve conceptual alignment. However, this does not mean that they have achieved evaluative alignment as they may still diverge in their judgment or evaluation of the imminent marriage between Mary and Gary. While conceptual alignment is a prerequisite, or at least a facilitating condition, for shared reality, evaluative alignment would be an additional, critical feature of a full-blown shared reality.

Certainly, there is no a priori reason why common ground has to be conceptualized to exclude the possible evaluative or attitudinal dimension of mutual understanding. Indeed, as noted above, the lead article is sympathetic to a broader, social psychological understanding of common ground. However, the notion of common ground has been designed for answering specific research questions about the possibility of common understanding of what something is and how it is referred to in conversation, rather than questions about evaluative or attitudinal alignment between communication partners.

I suspect that the distinction between conceptual and evaluative alignment in interpersonal communication has further implications that could be gauged by future work. To be sure, one can easily argue for the critical importance, or indispensability, of evaluation in human experience and behaviour in the material, social and cultural environment. Just like other organisms, humans need to make constant evaluations of stimuli in their environment to maximize their benefits or, at a minimum, to survive and reproduce. Other key motives, such as the motives for value, understanding (truth), and control, are closely associated with, or in the service of, satisfying this fundamental need (cf. Higgins, 2012). Thus, it may support theorizing about the communicative achievement of commonalities to consider processes underlying evaluative alignment. In so doing, approaches to interpersonal communication and conversation could profit from taking into account more systematically far-flung approaches in social influence, attitude change and persuasion, which, in turn, could be extended by integrating the role of basic communication processes, such as those described by Kashima. However, one should also reckon with notorious barriers to the achievement of evaluative alignment. Such barriers seem especially high in the arena of political issues and debate, where deeply rooted prejudice or conflicts over different (moral, religious) attitudes and values are difficult to overcome (e.g. Deutsch, Coleman \& Marcus, 2006; Liu, Sibley \& Huang, 2014).

The second, and briefer, of my comments relates to the role of memory processes in the formation and transmission of cultural knowledge. Memory forms an indispensable basis of much of cognition (Echterhoff, 2011), and I welcome the close consideration of memory processes in the lead article. In one section, Kashima (2014) points out that extant models of distributed knowledge representations can capture the memory mechanisms underlying generalization of common ground. Conversely, as a result of these mechanisms, knowledge that is grounded in one context but that is not cued by subsequent new contexts becomes relatively less accessible. It is 'screened out' from the dominant cultural knowledge base.

I suggest that another mechanism that could contribute to such gradual erasure of information from individual and thus cultural knowledge is socially shared retrieval-induced forgetting (RIF), a phenomenon that epitomizes the interplay of conversation and memory processes. At an intrapersonal level, RIF occurs when the selective retrieval of information or details about an event or topic induces forgetting of the unmentioned, but related, information or details (Anderson \& Levy, 2007). To the extent that conversations typically emphasize some details or information about events and topics, but omit other details or information, conversations involve selective retrieval, which is likely to elicit RIF (see Hirst \& Echterhoff, 2012). RIF can emerge for both the speaker (within-individual RIF) and the listener in a conversation (Stone, Coman, Brown, Koppel \& Hirst, 2012). The spread of memory inhibition from speaker to listener results in shared inhibition of unmentioned material in both interlocutors.

Socially shared RIF has been documented for freeflowing conversations (Cuc, Koppel \& Hirst, 2007) and a wide range of materials, such as stories (Cuc et al., 2007), autobiographical experiences (Stone, Barnier, Sutton \& Hirst, 2010) and shocking public events (Coman, Manier \& Hirst, 2009). Of particular relevance to the present topic, it has been shown that induced forgetting can spread through social networks to subsequent conversations (Coman \& Hirst, 2012). Hence, conversational silences could contribute significantly to the selection and streamlining of cultural knowledge at a collective level.

\section{References}

Anderson, M. C. \& Levy, B. J. (2007). Theoretical issues in inhibition: Insights from research on human memory. In: M. C. Anderson \& B. J. Levy, eds. Inhibition in
Cognition, pp. 81-102. Washington, DC: APA.

Brennan, S. E. (1998). The grounding problem in conversation with and through computers. In: S. R. Fussell \& R. J. Kreuz, eds. Social and Cognitive Psychological
Approaches to Interpersonal Communication, pp. 201-225. Hillsdale, NJ: Lawrence Erlbaum.

Brennan, S. E. \& Clark, H. H. (1996). Conceptual pacts and lexical choice in conversation. Journal of Experimental Social Psychology: 
Learning, Memory, and Cognition, 22, 1482-1493.

Chiu, C. Y. \& Hong, Y.-Y. (2007). Cultural processes: Basic principles. In: A. W. Kruglanski \& E. T. Higgins, eds. Social Psychology: Handbook of Basic Principles, 2nd edn, pp. 785-804. New York: Guilford.

Clark, H. H. \& Carlson, T. B. (1981). Context for comprehension. In: J. Long \& A. Baddeley, eds. Attention and Performance, Vol. IX, pp. 313-331. Hillsdale, NJ: Erlbaum.

Clark, H. H. \& Schaefer, E. F. (1989). Contributing to discourse. Cognitive Science, 13, 259-294.

Clark, H. H. \& Wilkes-Gibbs, D. (1986). Referring as a collaborative process. Cognition, 22, 1-39.

Coman, A. \& Hirst, W. (2012). The propagation of socially shared retrieval induced forgetting in social networks. Journal of Experimental Psychology: General, 141, 321-336.

Coman, A., Manier, D. \& Hirst, W. (2009). Forgetting the unforgettable through conversation: Socially shared retrieval-induced forgetting of September 11 memories. Psychological Science, 20, 627-633.

Cuc, A., Koppel, J. \& Hirst, W. (2007). Silence is not golden: A case for socially shared retrieval-induced forgetting. Psychological Science, 18, 727-737.

Deutsch, M., Coleman, P. T. \& Marcus, E. C. (2006). The Handbook of Conflict Resolution: Theory and Practice, 2nd edn, San Francisco: Jossey-Bass.

Dilthey, W. (1894). Ideen über eine beschreibende und zergliedernde Psychologie [Ideas for a descriptive and analytical psychology]. In: G. Misch, ed. Gesammelte Schriften, Bd. V, pp. 139-240. Göttingen: Vandenhoeck \& Ruprecht. Transl. R. M. Zaner \& K. L. Heiges (1977), Descriptive Psychology and Historical Understanding. The Hague: Nijhoff.

Echterhoff, G. (2010). Shared reality: Antecedents, processes, consequences. Social Cognition, 40, 273-276.

Echterhoff, G. (2011). The pervasiveness of memory. Culture \& Psychology, 17, 3-9.

Echterhoff, G., Higgins, E. T. \& Groll, S. (2005). Audience-tuning effects on memory: The role of shared reality. Journal of Personality and Social Psychology, 89, 257-276.

Echterhoff, G., Higgins, E. T., Kopietz, R. \& Groll, S. (2008). How communication goals determine when audience tuning biases memory. Journal of Experimental Psychology: General, 137, 3-21.

Echterhoff, G., Higgins, E. T. \& Levine, J. M. (2009). Shared reality: Experiencing commonality with others' inner states about the world. Perspectives on Psychological Science, 4, 496-521.

Echterhoff, G., Kopietz, R. \& Higgins, E. T. (2013). Adjusting shared reality: Communicators' memory changes as their connection with their audience changes. Social Cognition, 31, 162-186.

Echterhoff, G., Lang, S., Krämer, N. \& Higgins, E. T. (2009). Audience-tuning effects on communicators' memory: The role of audience status in sharing reality. Social Psychology, 40, 150-163.

Higgins, E. T. (2012). Beyond Pleasure and Pain: How Motivation Works. New York: Oxford University Press.
Hirst, W. \& Echterhoff, G. (2012). Remembering in conversation: The social sharing and reshaping of memories. Annual Review of Psychology, 63, 55-79.

Kashima, Y. (2014). Meaning, grounding, and the construction of social reality. Asian Journal of Social Psychology, 17, 81-95.

Kopietz, R., Hellmann, J. H., Higgins, E. T. \& Echterhoff, G. (2010). Shared-reality effects on memory: Communicating to fulfill epistemic needs. Social Cognition, 28, $353-$ 378.

Liu, J. H., Sibley, C. G. \& Huang, L. L. (2014). History matters: The impact of culturespecific symbols on political attitudes and intergroup relations. Political Psychology, 35, 57-79.

Pickering, M. J. \& Garrod, S. (2004). Toward a mechanistic psychology of dialogue. Behavioral and Brain Sciences, 27, 169225.

Schober, M. F. \& Clark, H. H. (1989). Understanding by addressees and overhearers. Cognitive Psychology, 21, 211-232.

Stalnaker, R. C. (1978). Assertion. In: P. Cole, ed. Syntax and Semantics: Pragmatics, vol. 9, pp. 315-332. New York: Academic Press.

Stone, C. B., Barnier, A. J., Sutton, J. \& Hirst, W. (2010). Building consensus about the past: Schema consistency and convergence in socially shared retrieval-induced forgetting. Memory, 18, 170-184.

Stone, C. B., Coman, A., Brown, A. D., Koppel, J. \& Hirst, W. (2012). Toward a science of silence: The consequences of leaving a memory unsaid. Perspectives on Psychological Science, 7, 39-53. 